Results: Of the 519 enrolled pts, 504 (with complete data on the FiRST questionnaire) were analyzed at M3. A positive screening for comorbid FM was found in 192 pts $(38 \%)$ at M0 and in $127(25 \%)$ pts at M3. Correlation between FiRST at M0 and M3 was weak with a Kappa coefficient correlation of $0.4[0,3$ 0,5].

Four groups were identified: group $[+/+]$ with comorbid $\mathrm{FM}$ at $\mathrm{M0}$ and $\mathrm{M3}: \mathrm{N}=93$ (18\%; group [+/-] with comorbid FM at M0 but not at M3: N=99 (20\%); group [-/] without comorbid FM at M0 and M3: $\mathrm{N}=278(55 \%)$; group $[-/+]$ without comorbid FM at $\mathrm{M0}$ but at $\mathrm{M} 3: \mathrm{N}=34(7 \%)$

Changes in the status of comorbid FM (disappearance or appearance) was observed in 134 pts (26\%). In the 193 pts with baseline comorbid FM, after 3 months of anti-TNF treatment, comorbid FM was no longer found in 99 $(51 \%) \%$.Efficacy at M3 was significantly better, according to BASDAI 50 , in patients without comorbid FM at M3 (Table).

\begin{tabular}{lcccc}
\hline & \multicolumn{4}{c}{ FM status according to the FIRST questionnaire at M0/M3 } \\
& \multicolumn{5}{c}{$(\mathrm{N}$ total=504) } \\
\cline { 2 - 5 } & $+/+$ & $+/-$ & $-/-$ & $-/+$ \\
\hline $\begin{array}{l}\text { Number of patients } \\
\begin{array}{l}\text { Number of patients reaching } \\
\text { BASDAl 50 at M3 }\end{array}\end{array}$ & 93 & 99 & 278 & 34 \\
\hline
\end{tabular}

Conclusions: There is a high frequency of comorbid FM screened by the FiRST in active axSpA, decreased by $51 \%$ f after 3 months of anti-TNF treatments. Persistence of FM after 3 months of anti-TNF treatment is associated with lower anti-TNF response. Further studies are required to analyze the impact of screening FM before starting anti-TNF therapy in axSpA.

References:

[1] Perrot $S$, et al. Development and validation of the Fibromyalgia Rapid Screening Tool (FiRST). Pain. 2010;150:250-6.

Acknowledgements: This study was conducted thanks to an unrestricted grant from MSD.

Disclosure of Interest: None declared

DOI: 10.1136/annrheumdis-2017-eular.4688

\section{THU0483 CHARACTERISTICS OF PATIENTS WITH ACTIVE AXIAL SPONDYLOARTHRITIS AND COMORBID FIBROMYALGIA. DIFFERENCES ACCORDING TO FIBROMYALGIA SCREENING (FIRST QUESTIONNAIRE) AND FIBROMYALGIA CLASSIFICATION (ACR1990)}

S. Perrot, A. Moltó, A. Etcheto, N. Boudersa, P. Claudepierre, N. Roux, F. Berenbaum, A. Martin, L. Sparsa, P. Coquerelle, M. Soubrier, L. Gossec, M. Dougados. Predict-SpA Study Group, Paris, France

Background: Fibromyalgia (FM) can be a comorbid condition in axial spondyloarthritis (axSpA). FM screening questionnaires and classification criteria fulfillment may demonstrate different prevalence and patients' characteristics may differ.

Objectives: To evaluate frequency of comorbid FM, and the differences between axSpA patients with/without comorbid FM according to screening (FiRST) and classification tools (ACR1990 FM criteria)

Methods: A multicenter national study involving 39 rheumatology centers in France included 519 patients with axSpA starting an anti-TNF treatment (PredictSpA study; ClinicalTrials.gov: NCT03039088). Patients (pts) were screened for FM with the FiRST questionnaire and classified as FM by ACR 1990 criteria. Demographic characteristics, comorbidities, axSpA characteristics, CRP and imaging were recorded in all patients. Kappa coefficient (and its $95 \% \mathrm{Cl}$ ) was calculated to compare FiRST and ACR1990 criteria. Baseline characteristics associated with FM were evaluated by univariable and multivariable logistic regression (including the variables with a $p$ value $<0.20$ in the univariable analysis).

Results: In the 519 pts (females: $46 \%$, age: $42 \pm 12$ years, mean BASDAI $5.7 \pm 2.0$, mean ASDAS-CRP 3.3 \pm 0.9 ), a comorbid FM was screened in $38 \%$ and diagnosed in $16 \%$ of pts. Agreement between FiRST and ACR1990 was poor, with a Kappa coefficient of $0.2[0.2-0.3]$.

In the multivariable analysis, comorbid FM (by the FiRST questionnaire) in axSpA

Table 1

\begin{tabular}{lccc}
\hline Number of patients & \multicolumn{2}{c}{$\begin{array}{c}\text { Fibromyalgia according to } \\
\text { FiRST questionnaire }\end{array}$} & Odds-ratio [95\% Cl] \\
\cline { 2 - 3 } & yes (199) & no (320) & \\
\hline Education level (> high school) & $72(37 \%)$ & $163(51 \%)$ & $0,6[0,4-0,9]$ \\
Sick leave (yes) & $108(54 \%)$ & $134(42 \%)$ & $1,5[1,0-2,2]$ \\
Heel pain (yes) & $127(64 \%)$ & $151(47 \%)$ & $1,6[1,1-2,5]$ \\
Etanercept at baseline (yes) & $63(32 \%)$ & $137(43 \%)$ & $0,6[0,4-0,9]$ \\
\hline
\end{tabular}

Table 2

\begin{tabular}{llcr}
\hline \multirow{2}{*}{ Number of patients } & \multicolumn{2}{c}{ Fibromyalgia according to } & Odds-ratio [95\% Cl] \\
\cline { 2 - 3 } & yes (84) & no $(435)$ & \\
\hline HLA B27 (positive) & $27(32 \%)$ & $272(63 \%)$ & $0.39[0.22-0.68]$ \\
Heel pain (yes) & $61(73 \%)$ & $217(50 \%)$ & $2.03[1.16-3.56]$ \\
\hline
\end{tabular}

patients was independently associated with a lower education level, more sick leave, more heel pain, more frequent second line anti-TNF. Comorbid FM defined by the ACR1990 classification criteria was independently associated with heel pain and inversely associated with B27 haplotype. (Table)

Conclusions: $\mathrm{FM}$ is frequently associated with active axSpA, with poor correlation between screening (FiRST) and diagnosis (ACR1990) test. Several characteristics are associated with comorbid FM, depending on FM classification and screening tools.

References:

[1] Perrot S et al. Development and validation of the Fibromyalgia Rapid Screening Tool (FiRST). Pain. 2010;150:250-6.

Acknowledgements: This study was conducted thanks to an unrestricted grant from MSD.

Disclosure of Interest: None declared

DOI: 10.1136/annrheumdis-2017-eular.4702

\section{THURSDAY, 15 JUNE 2017 \\ Basic science in paediatric rheumatology}

\section{THU0484 RO60 EXPRESSION DECREASES WITH AGE IN PERIPHERAL BLOOD MONONUCLEAR CELLS OF CHILDREN AND ADOLESCENTS AND CORRELATES WITH TLR7 STIMULATION IN PDCS OF PREPUBERTAL CHILDREN}

A. Radziszewska, K. Webb, H. Peckham, Y. loannou. Arthritis Research UK Centre for Adolescent Rheumatology at University College London, Great Ormond Street Hospital and UCLH, University College London, London, United Kingdom

Background: Auto-antibodies to the RNA binding protein Ro60 are present in patients with autoimmune disorders such as systemic lupus erythematosus (SLE). In addition to its established role as an auto-antigen, Ro60 has been found to bind Alu RNA retroelements whereby it may target Alu retroelement RNA for degradation suggesting a novel putative function of this auto-antigen. If Ro60 modulates the amount of cellular RNA then one may hypothesise an association with toll-like receptor (TLR) 7 stimulation threshold.

Objectives: To measure the physiological levels of intracellular Ro60 protein in healthy children and adolescents and investigate a possible link between Ro60 protein expression and interferon- $\alpha$ (IFN- $\alpha$ ) production after TLR7 stimulation. Methods: Peripheral blood mononuclear cells (PBMCs) were isolated from blood from 48 healthy children and adolescents (age range 6.7-17.9 years old). Cell lysates from thawed PBMC samples were tested for Ro60 expression by Western blot. PBMCs were also stimulated for 20 hours with TLR7/8 agonist R848, at $1 \mathrm{ug} / \mathrm{ml}$ in the presence of brefeldin $\mathrm{A}$, and plasmacytoid dendritic cell $(\mathrm{pDC})$ IFN- $\alpha$ expression was measured using flow cytometry. Statistical tests to measure correlation between IFN- $\alpha$ expression in (pDCs) and PBMC Ro60 expression were performed using SPSS.

Results: Ro60 expression in PBMCs correlated negatively with age (Spearman's rho $=-0.317, p=0.032$ ). When participants were divided into two groups based on their self-reported puberty status, Ro60 expression was higher in the pre-pubertal group $(\mathrm{p}=0.02)$. There was, however, no difference in Ro60 expression between males and females $(p=0.44)$ or when sexes were stratified according to pubertal status. $\mathrm{pDC}$ IFN- $\alpha$ production after TLR 7 stimulation, did not correlate with ex vivo PBMC Ro60 expression overall (Spearman's rho $=0.159, p=0.302$ ) however a moderate positive correlation was observed in pre-pubertal samples only (Spearman's rho $=0.554, p=0.021$ ).

Conclusions: Ro60 expression decreases with age in healthy young people. These findings need to be confirmed in a larger cohort and further studies are necessary to investigate the link between Ro60 expression and TLR7 signalling across different age groups as well as in patients with SLE.

Disclosure of Interest: None declared

DOI: 10.1136/annrheumdis-2017-eular.5073

\section{THU0485 POLYMORPHISM OF SOME GENES INVOLVED IN IMMUNE AND INFLAMMATORY RESPONSES IN BELARUSIAN PATIENTS WITH JUVENILE IDIOPATHIC ARTHRITIS AND OTHER ARTICULAR PATHOLOGY}

H.A. Yatskiu ${ }^{1}$, N.V. Nikitchenko ${ }^{1}$, N.V. Savina ${ }^{1}$, T.D. Kuzhir ${ }^{1}$, A.M. Tchitchko ${ }^{2}$ A.V. Sukalo ${ }^{2}$, R.I. Goncharova ${ }^{1} .{ }^{1}$ Institute of Genetics and Cytology, National Academy of Sciences of Belarus; ${ }^{2}$ Belarusian State Medical University, Minsk, Belarus

Background: Etiology and pathogenesis of juvenile idiopathic arthritis (JIA), which prevails among pediatric rheumatic diseases, are insufficiently clear. The study of molecular-genetic basis of JIA is of great interest for revealing genetic predisposition and early diagnosis.

Objectives: The present study aimed to analyze seven SNPs in five genes involved in immune and inflammatory responses: TNF $\alpha$ (rs1800629, rs361525), PTPN22 (rs24766012), MIF (rs755622, rs5844572), CTLA4 (rs5742909), STAT4 (rs7574865), as well as in two DNA repair genes XPD (rs1799793) and XRCC1 (rs25487) in different conditions. 